\title{
Polymorphic segmental duplications at 8p23.I challenge the determination of individual defensin gene repertoires and the assembly of a contiguous human reference sequence Stefan Taudien*1, Petra Galgoczy ${ }^{1}$, Klaus Huse ${ }^{1}$, Kathrin Reichwald ${ }^{1}$, Markus Schilhabel ${ }^{1}$, Karol Szafranski ${ }^{1}$, Atsushi Shimizu ${ }^{2}$, Shuichi Asakawa ${ }^{2}$, Adam Frankish ${ }^{3}$, Ivan F Loncarevic ${ }^{4}$, Nobuyoshi Shimizu ${ }^{2}$, Roman Siddiqui ${ }^{1}$ and Matthias Platzer ${ }^{1}$
}

Address: ${ }^{1}$ Genomanalyse, Institut für Molekulare Biotechnologie, Beutenbergstr. 11, D-07745 Jena, Germany, ${ }^{2}$ Keio University School of Medicine, 35 Shinanomachi, Shinjuku-ku, Tokyo 160-8582, Japan, ${ }^{3}$ Wellcome Trust Sanger Institute, Hinxton Cambridge CB10 1SA, UK and ${ }^{4}$ Institut für Humangenetik und Anthropologie, Friedrich-Schiller-Universität Jena, Kollegiengasse 10, D-07743 Jena, Germany

Email: Stefan Taudien* - stau@imb-jena.de; Petra Galgoczy - pgal@frk1.ukl.uni-freiburg.de; Klaus Huse - khuse@imb-jena.de; Kathrin Reichwald - kathrinr@imb-jena.de; Markus Schilhabel - mbs@imb-jena.de; Karol Szafranski - karol@pcbi.upenn.edu; Atsushi Shimizu - atsushis@dmb.med.keio.ac.jp; Shuichi Asakawa - asa@dmb.med.keio.ac.jp; Adam Frankish - af2@sanger.ac.uk; Ivan F Loncarevic - Ivan.Loncarevic@mti.uni-jena.de; Nobuyoshi Shimizu - shimizu@dmb.med.keio.ac.jp; Roman Siddiqui - rsidd@imbjena.de; Matthias Platzer - mplatzer@imb-jena.de

* Corresponding author

Published: 10 December 2004

BMC Genomics 2004, 5:92 doi:10.1 |86/|47|-2|64-5-92
Received: 25 August 2004

Accepted: 10 December 2004

This article is available from: http://www.biomedcentral.com/I47I-2 I64/5/92

(C) 2004 Taudien et al; licensee BioMed Central Ltd.

This is an Open Access article distributed under the terms of the Creative Commons Attribution License (http://creativecommons.org/licenses/by/2.0), which permits unrestricted use, distribution, and reproduction in any medium, provided the original work is properly cited.

\begin{abstract}
Background: Defensins are important components of innate immunity to combat bacterial and viral infections, and can even elicit antitumor responses. Clusters of defensin (DEF) genes are located in a $2 \mathrm{Mb}$ range of the human chromosome 8p23.I. This DEF locus, however, represents one of the regions in the euchromatic part of the final human genome sequence which contains segmental duplications, and recalcitrant gaps indicating high structural dynamics.

Results: We find that inter- and intraindividual genetic variations within this locus prevent a correct automatic assembly of the human reference genome (NCBI Build 34) which currently even contains misassemblies. Manual clone-by-clone alignment and gene annotation as well as repeat and SNP/haplotype analyses result in an alternative alignment significantly improving the DEF locus representation. Our assembly better reflects the experimentally verified variability of DEF gene and DEF cluster copy numbers. It contains an additional DEF cluster which we propose to reside between two already known clusters. Furthermore, manual annotation revealed a novel DEF gene and several pseudogenes expanding the hitherto known DEF repertoire. Analyses of BAC and working draft sequences of the chimpanzee indicates that its DEF region is also complex as in humans and DEF genes and a cluster are multiplied. Comparative analysis of human and chimpanzee DEF genes identified differences affecting the protein structure. Whether this might contribute to differences in disease susceptibility between man and ape remains to be solved. For the determination of individual DEF gene repertoires we provide a molecular approach based on DEF haplotypes.

Conclusions: Complexity and variability seem to be essential genomic features of the human DEF locus at 8p23.I and provides an ongoing challenge for the best possible representation in the human reference sequence. Dissection of paralogous sequence variations, duplicon SNPs ans multisite variations as well as haplotypes by sequencing based methods is the way for future studies of interindividual DEF locus variability and its disease association.
\end{abstract}




\section{Background}

Despite the tremendous efforts and successful completion of the Human Genome Project by April 14 $4^{\text {th }} 2003$, a set of recalcitrant gaps remain in the euchromatic part of the final human genome sequence. One obvious reason for these gaps is that the appropriate regions are enriched in sequences that are not tolerated by the cloning systems. The second possibility is that even if clones are available and amenable for sequencing, their sequences cannot be unambiguously aligned due to gap flanking segmental duplications. Generally, those duplicons are defined by $>90 \%$ sequence identity and lengths of $>1 \mathrm{~kb}$ and about $87 \%$ of all human ones are longer than $50 \mathrm{~kb}$ [1]. In these regions with nucleotide identities up to $>99 \%$ over several $\mathrm{kb}$ it is nearly impossible to decide whether very similar sequences represent distinct loci or different alleles of a single locus. Here, sequencing of a single chromosomal haplotype is a straightforward approach to achieve a "consistent" assembly. It was successfully applied to decipher intrachromosomal duplications of the human Y [2]. If, however, duplications are located on autosomes and their copy numbers vary interindividually, as shown for regions in 15q11-q13 [3], the situation becomes even more complicated and requires the extra effort of resolving haplotype differences that result from the diploid nature of the underlying BAC library. In the Williams-Beuren syndrome (WBS) region on human chromosome 7, only extensive redundant sequencing from a single BAC library led to a representative sequence [4]. Alternatively, monospermic complete hydatidiform moles $[5,6]$ and hamster somatic cell hybrids [7] provide access to fully homozygous genomes or individual autosomes, respectively.

It is a fact that structural variations between chromosomal haplotypes complicate the sequence assembly and lead to the formation of de facto gaps [1,8]. The more haplotypes are represented by BAC clones, the more de facto gaps may be formed. In the case of unresolved segmental duplications, usually a large number of clones has been sequenced with high accuracy [9] and the clone coverage of the loci is well above-average of the entire human genome. However, no contiguous tiling path can be build and gaps remain. Nevertheless, the available data are an invaluable resource for the investigation of individual genetic variations in duplicated regions and of their association with diseases.

One of those complex regions is located in 8 p23.1 at 6.3 - 8.3 Mb of the July 2003 human reference sequence (NCBI Build 34; UCSC version hg16, Fig. 1A). In the Golden Path assembly [10], there are 22 finished clones from five different libraries and 20 working draft or predraft clones ( $<4 \mathrm{x}$ coverage shotgun; four different libraries) grouped on both sides of a recalcitrant gap at $7.5 \mathrm{Mb}$. Another 10 finished clones from four different libraries are not included in the hg16 assembly but map to the 8p23.1 locus. Several attempts to close this gap have failed due to the highly repetitive structure of the flanking sequences. The gap flanking regions harbor defensin (DEF) genes, encoding a group of small cationic peptides with characteristic three intramolecular disulfide bonds. These peptides play a prominent role in innate immunity to defend bacterial and viral infections in animals, plants and insects [11]. Furthermore, in humans, loss or down regulation of DEF genes is shown to be related with cancer, such as renal cell carcinoma [12-14], prostate cancer [14] and bladder tumors [15]. Two different DEF gene clusters can be distinguished: DEF cluster a contains the genes DEFB1, DEFA6, DEFA4, DEFA1, DEFT1, DEFA3 and DEFA5; DEF cluster $b$ comprises the genes DEFB109p, DEFB108， DEFB4， DEFB103，SPAG11， DEFB104, DEFB106, DEFB105, and DEFB107 (Fig. 2). DEF cluster b is duplicated in reverse complementary orientation on either side of the gap, forming the distal cluster $b 1$ and the proximal cluster $b 2$.

Interestingly, the DEF cluster region was identified as the distal breakpoint (REPD) of a 4.7-Mb segment inversion, identified as a common polymorphism with frequencies of $39 \%$ and $26 \%$ in the Japanese population and in Europeans, respectively [16-18]. Although the inversion itself apparently do not have any pathological effects, in heterozygous female carriers unequal recombinations can occur, leading to three macrorearrangements - inv dup del (8p); +der(8)(8p23.1pter) and del (8)(p23.1p23.2) related to severe disease phenotypes. The fact that low copy repeats (LCR) flanking the DEF clusters represent the essential sites for such recombination events is a strong argument to resolve the structure of the LCRs themselves as well as the genomic organization of the entire region. Also, genes of both DEF cluster $a$ and $b$ vary interindividually in their copy numbers. This was shown by somatic cell hybrid mapping for DEFA1, DEFA3 (DEF cluster a; 23 copies each) [19] and by a combination of multiplex amplifiable probe hybridisation and semiquantitative fluorescence in situ hybridization for DEFB4, DEFB103, DEFB104 (DEF cluster $b$; 2-12 copies each) [20]. It is generally assumed that this variability crucially contributes to the differences in the innate immunity network between individuals and influences predisposition and susceptibility for diseases.

The polymorphic nature of this locus suggested to us that the pool of clones presented in the hg16 assembly should be aligned in a different way. Our alternative assembly creates more DEF cluster copies and better reflects the individual variability of the locus. In addition, comparative sequence analysis of DEF genes in our closest relative, the chimpanzee (Pan troglodytes), both revealed the differences in the defensin protein panel of both species 


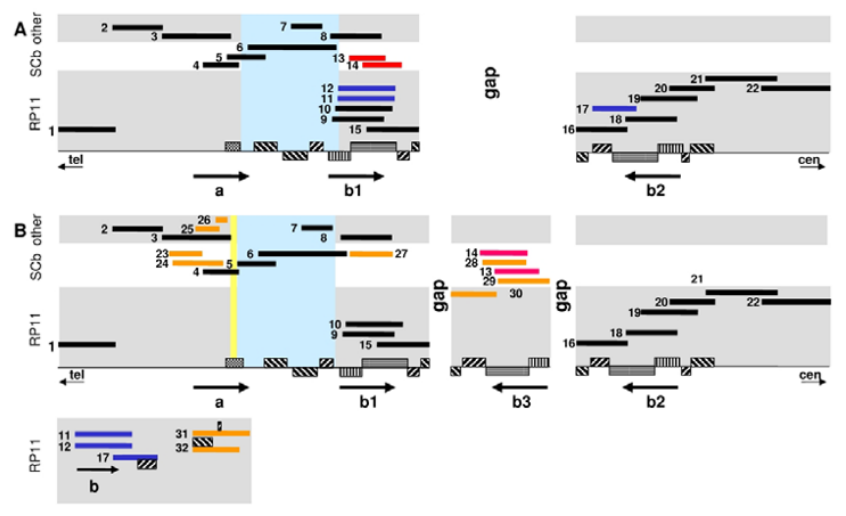

Figure I

Alternative alignments of the 8p23.I DEF locus. $(A)$ July 2003 UCSC version hg 16 [10] chr8:6,258,283-8,262,034. Only finished clones are shown and arranged by libraries, which are indicated by background colors: RPII = gray, bottom; $\mathrm{SCb}=$ white, middle; other (CTB, CTD, GS, RPI3) = gray, top. Defensin gene clusters are shown as arrows, repeat blocks are indicated as striped boxes, $(+)$ strand is above the black line, (-) strand is below the black line, same stripe patterns indicate similar structures. The light blue background indicates the distal repeat region for chromosomal rearrangements [16]. (B) Revised alignment of the 8p23.I DEF locus, containing an additional 360-kb-contig and five clones which cannot be aligned; colors: black $=$ aligned as in Fig. IA; orange = clones not present in the UCSC browser; red = clones with different positions in both alignments, blue $=$ clones presented in the UCSC browser but excluded in the revised assembly. The yellow vertical bar in DEF a illustrates the widening of the DEF cluster $a$ as a result of the alternative alignment of [GenBank:AF200455] / [GenBank:AF238378] (see text). Clone (number) GenBank accession.version / library: (I) [GenBank:AC0 I8398] / RPII, (2) [GenBank:AF287957] / CTD, (3) [GenBank:AF233439] / GS, CTD, (4) [GenBank:AF200455] / SCb, (5) [Gen-

Bank:AF238378] / SCb, (6) [GenBank:AF228730] / SCb, CTB, (7) [GenBank:AF2 I5847] / CTB, (8) [GenBank:ACI 30339] / RPI3, (9) [GenBank:ACI30360] / RPII, (I0) [Gen-

Bank:ACI 30367] / RPII, (II) [GenBank:ACI 34395] / RPI I, (I2) [GenBank:ACI 34683] / RPI I, (I3) [GenBank:AC285443] / SCb, (14) [GenBank:AC20203 I] / SCb, (15) [GenBank:ACI 34684] / RPI I, (I6) [GenBank:AC084I2I] / RPII, (I7) [GenBank:ACI 44950] / RPI I, (18) [GenBank:ACI30365] / RPI I, (19) [GenBank:ACI 3 I 269] / RPI I, (20) [GenBank:ACl 05233] / RPI I, (2I) [GenBank:AC068020] / RPI I, (22) [GenBank:AC068353] / RPI I, (23) [GenBank:AF298854] / SCb, (24) [GenBank:AF205406] / SCb, (25) [GenBank:AF3 I 4060] / GS, (26) [GenBank:AF3। 4059] / SCb, (27) [Gen-

Bank:AF25283 I] / SCb, (28) [GenBank:AFI 89745] / SCb, (29) [GenBank:AF252830] / SCb, (30) [GenBank:ACI 48I06] / RPII, (3I) [GenBank:ACI052I4] / RPI I, (32) [GenBank:AC092766] / RPI I

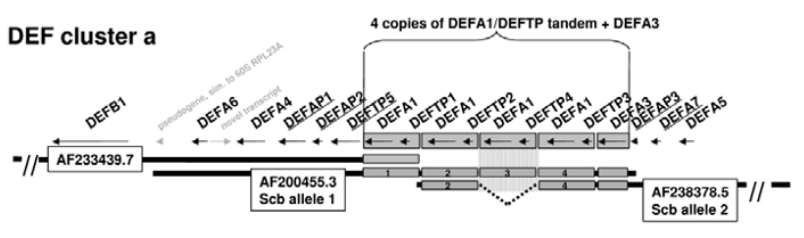

DEF cluster b

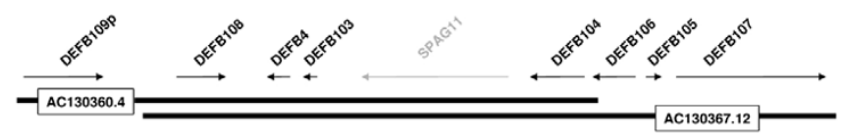

Figure 2

Genes and pseudogenes in DEF clusters $a$ and $b$. Names correspond to the Vertebrate Genome Annotation, intergenic distances are scaled I:I0. Defensin and defensin like genes and pseudogenes are written in black, novel defensin genes and pseudogenes are underlined, other genes / transcripts are indicated in gray. DEF cluster a: The presence of four copies of the DEFAI/DEFTP tandem and the DEFA3 gene in [GenBank:AF200455] requires the illustrated clone alignment, resulting in a "widening" of the hgl 6 assembly, pictured by the striped gray box (corresponding to the yellow bar in Fig. I). Analysis of the intergenic distances (data not shown) suggests, that [GenBank:AF238378] harbors copies 2 and 4 of the DEFA IIDEFTP tandem whereas copy 3 is missing (dotted line). Since both clones are derived from the same library $(\mathrm{SCb})$, either copy 3 is lost during the cloning process or the clones represent different alleles. DEF cluster b: The DEF cluster $b$ is illustrated in the orientation of DEF cluster $b I$.

and showed that DEF clusters are also multiplied in the ape.

Moreover, extraction of single nucleotide polymorphisms (SNPs) from overlapping regions of clones harboring DEF genes provided haplotypes which were analyzed for their ratio in individuals and used for the determination of individual gene copy numbers.

\section{Results}

\section{Revision of the hgl6 assembly}

In the framework of the International Human Genome Sequencing Consortium we sequenced 19 out of 32 BAC clones mapping to the 8p23.1 DEF region (for linking clone numbers with accession numbers see legend of Fig. 1 ; accession numbers and corresponding clone names are given in Additional file 1). In addition to the existing clone alignments of DEF clusters b1 and b2, in our sequence assembly a consistent 360 -kb-contig comprising five clones was built that also contains a DEF cluster $b$. Interestingly, this additional contig could neither be joined unambiguously to cluster $b 1$ nor to cluster $b 2$. This is in contradiction to the hg16 assembly where clones 13 and 14 of the novel contig are positioned in DEF cluster b1. 
This disagreement prompted us to evaluate carefully the alignment of the entire region. For this, we used all 32 finished clones which map in the region. To circumvent the problems of an automatic assembly in repeat rich, duplicated regions, the clones were manually joined according to the following criteria: only single base exchanges and insertions/deletions in repeat stretches were tolerated and joins were not performed if the total ratio of single base differences in the overlapping clone portions was $>0.8 \%$.

The result is an alternative alignment shown in Fig. 1B, which differs from the hg16 assembly in three major points and is supported by a detailed repeat and SNP/ haplotype analysis:

(1) Clones 23-27 not present in the hg16 assembly were located distally of the gap, whereas clones 11,12 and 17 were excluded since they cannot be aligned according to our criteria. Clones 13 and 14 were moved to the new 360-kb-contig (see below).

(2) In the framework of the human and vertebrate analysis and annotation initiative (HAVANA) [21], where gene structures are annotated on the basis of human interpretation of combined supportive evidence generated during sequence analysis, we manually annotated seven DEF gene containing clones, five of them located in DEF cluster $a$. We found that clone 4 contains four copies of a DEFA1 / DEFTP tandem and one copy of DEFA3, whereas clone 5 harbors only two DEFA1 / DEFTP tandems and the DEFA3 gene (Fig. 2). Consequently, in our assembly, clone 4 is aligned to clone 5 in a way that results in four copies of the DEFA1/DEFTP tandem instead of three copies in the hg16 assembly. Thus, this region will be "widened" by shifting all proximally adjacent clones for 23,270 bp. Analysis of the intergenic distances between the DEF genes suggests that clone 5 harbors copies 2 and 4 of the four DEFA1 / DEFTP tandems. Furthermore, hitherto undiscovered, additional DEF genes and pseudogenes could be annotated: clones 3-5 harbor the DEFA7 gene [GenBank:A98570], [GenBank:A98571] coding for a novel protein, similar to DEFA4, as well as pseudogenes DEFAP1, DEFAP2 and DEFAP3 similar to DEFA (Fig. 2). Our annotation of the entire DEF cluster region is submitted to the Vertebrate Genome Annotation database [22].

(3) Our assembly of the 32 finished clones mapping to the locus created an additional 360-kb-contig which consists of five clones representing an additional, third DEF cluster copy named b3. Since the repeat in clone 30 is located on the (-)-strand, the contig cannot be joined to any of the repeats at either side of the gap but instead has to be located within the gap in unknown orientation.

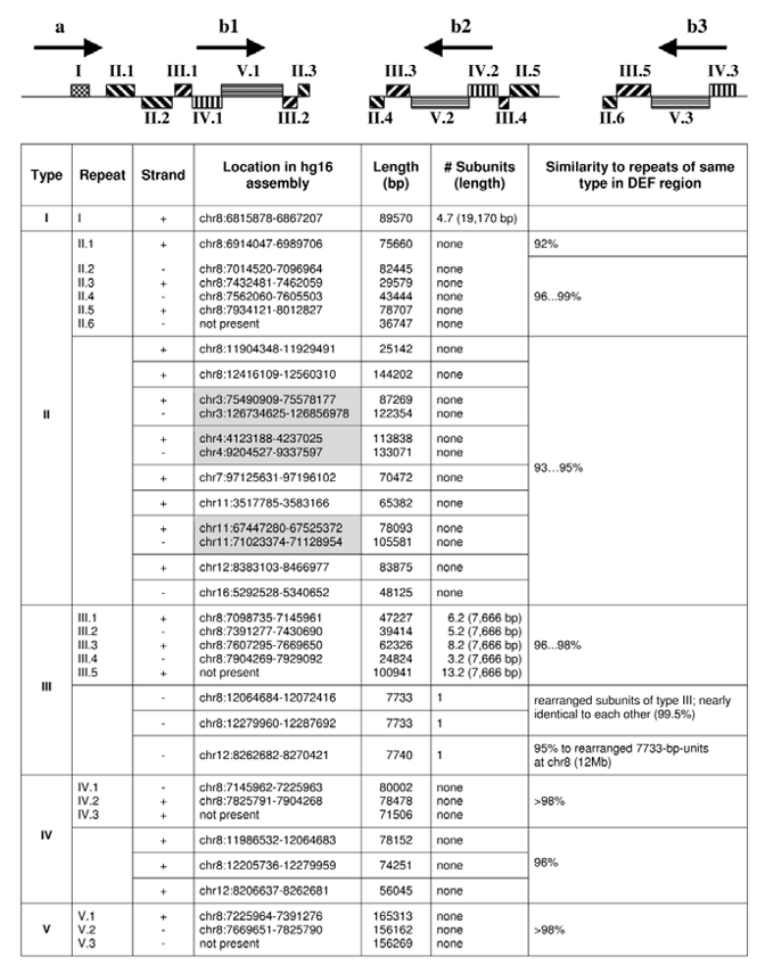

Figure 3

DEF gene cluster flanking repeat blocks in 8p23.I and their paralogs on other genomic loci. Repeats and repeat clusters are drawn as striped bars as in Fig. I. Inverted repeat pairs of the paralogs are highlighted in gray.

\section{Low copy repeat analysis}

The DEF locus contains several genomewide low copy repeats (LCR) (Fig. 3). The repeats form clusters of up to $165 \mathrm{~kb}$ length and paralogs exist on other chromosomes as well as on chromosome 8 at about $12 \mathrm{Mb}$. In silico identification of these paralogs was in good accordance with fluorescence in situ hybridization (FISH) experiments using clones from the 8p23.1 DEF locus as probes (Additional files 3 and 4). Five types of LCRs can be distinguished:

\section{Type I}

The $89.6 \mathrm{~kb}$ cluster consists of 4.7 subunits of a $19.2 \mathrm{~kb}$ repeat. Each complete subunit contains DEFA1 and DEFTP. The incomplete fifth copy harbors DEFA3. The content of interspersed repeats is low $(20 \%)$; the nucleotide identity between the subunits is $99 \%$. The repeat subunits of cluster I are unique to this locus and do not show significant homologies to other regions of the human genome. 
Type II

Repeats of type II flank DEF clusters $b$, do not show substructures and do not contain genes. In contrast to repeat units of type I they differ in length and orientation, contain inversions and show a high degree of interspersed repeats (55\%). The considerable length differences are caused by an initial partial duplication and/or subsequent deletions. The nucleotide identity of the repeats is 9699\% except for II.1, located adjacent to DEF cluster $a$, which exhibits an identity of $\sim 92 \%$ to repeats II.2-6.

Blat search of the longest repeat (II.2, $82 \mathrm{~kb}$ ) revealed that repeats of type II are also present at about $12 \mathrm{Mb}$ on chromosome 8p23.1 as well as on other human chromosomes, e.g. 3, 4, 7, 11, 12 and 16. The paralogs vary in length (25-133 kb) and show nucleotide identities of 93$95 \%$ compared to II.2 on 8p23.1. On chromosomes 3, 4 and 11 , they are arranged as inverted repeats. The distances in between "repeat pairs" vary remarkably: Whereas in 11q13.2-11q13.4 and 4p16.2-16.1 the parts are separated by 4 and $5 \mathrm{Mb}$, respectively, the repeats on chromosome 3 are located in 3p12.3 and 3q13.31, framing $51 \mathrm{Mb}$ on both arms of the chromosome.

Type III

Located adjacent to DEF clusters $b$, they differ in length and orientation and consist of various numbers of $7.7 \mathrm{~kb}$-subunits showing a low content of interspersed repeats $(17 \%)$. The nucleotide identity of two subunits of a single type III cluster is $>99 \%$, whereas the identity of two subunits of different clusters is in the range of 96-98\%. Each of the $7.7 \mathrm{~kb}$-subunits harbors one copy of a gene for the hypothetical protein FLJ10408 [GenBank:NM_018088]. The coding sequences of the gene copies differ and in some cases the reading frame contains premature termination codons. Blat search of the type III repeat subunit revealed three paralogs in the human genome. Two of these are located on chromosome 8p23.1 at about $12 \mathrm{Mb}$ (flanked by repeats of type II), the third at 12p13.31. The paralogs are slightly rearranged in comparison to the subunits of III.1-5.

\section{Type IV}

Repeats of this type partially cover the DEF clusters $b$ (containing DEFB109P and DEFB108, Fig. 2) and do not show substructures. The content of interspersed repeats is about $30 \%$; the nucleotide identity between repeats IV.1-3 is $>98 \%$. Paralogs of these repeats exist on chromosome 8 at about $12 \mathrm{Mb}$ and on chromosome 12 with identities of about $96 \%$ to IV1-3.

\section{Type $V$}

These repeats are unique to the 8 p23.1 DEF locus, show no substructures and contain 35-38\% interspersed repeats as well as the major part of the DEF cluster $b$ genes (all genes downstream of DEFB108, Fig. 2). The nucleotide identities between V.1, V.2 and V.3 are $>98 \%$.

Table I: SNPs and haplotypes $\mathrm{HI}-\mathrm{H} 6$ extracted from DEF cluster $b$ covering clones

\begin{tabular}{|c|c|c|c|c|c|c|c|c|}
\hline \multirow[t]{2}{*}{ Gene } & \multirow[t]{2}{*}{ Pos. mRNA' } & \multicolumn{6}{|c|}{ Haplotypes ${ }^{2}$} & \multirow[t]{2}{*}{ Change } \\
\hline & & HI & $\mathbf{H} 2$ & $\mathrm{H} 3$ & H4 & H5 & H6 & \\
\hline DEFBI07 & 13 & G & I & I & $\mathrm{T}$ & G & $\mathrm{T}$ & F5V \\
\hline DEFBI05 & 107 & C & 1 & C & $\mathrm{T}$ & C & C & P36L \\
\hline DEFBI06 & 125 & $\mathrm{~T}$ & 1 & C & $\mathrm{T}$ & $\mathrm{T}$ & $\mathrm{T}$ & Silent \\
\hline DEFBI 04 & 42 & $A$ & $A$ & A & $A$ & $A$ & G & VIOI \\
\hline \multirow[t]{4}{*}{ DEFB4 } & 78 & $\mathrm{~T}$ & $C$ & C & $C$ & C & C & Silent \\
\hline & 120 & $\mathrm{~T}$ & $\mathrm{~T}$ & $\mathrm{~T}$ & $\mathrm{~T}$ & $\mathrm{C}$ & $\mathrm{T}$ & Silent \\
\hline & 275 & C & $C$ & C & $C$ & $\mathrm{~T}$ & C & 3'UTR \\
\hline & 335 & C & $C$ & C & $C$ & G & C & 3'UTR \\
\hline \multirow[t]{3}{*}{ DEFBI08 } & 138 & $A$ & $A$ & $A$ & $A$ & $\mathrm{~T}$ & I & Silent \\
\hline & 111 & C & $C$ & $\mathrm{C}$ & $C$ & $\mathrm{~T}$ & I & Silent \\
\hline & 97 & G & G & A & $A$ & G & I & G33S \\
\hline \multirow[t]{5}{*}{ DEFBI09p } & 133 & A & A & A & 1 & G & I & V45I \\
\hline & 132 & C & $C$ & A & I & A & I & $\mathrm{K} 44 \mathrm{~N}$ \\
\hline & 119 & $C$ & $C$ & G & I & G & I & R40T \\
\hline & 104 & $\mathrm{~T}$ & $\mathrm{~T}$ & $\mathrm{C}$ & I & C & I & S35F \\
\hline & $4 I$ & $C$ & $C$ & 1 & I & A & 1 & SI4ochre \\
\hline
\end{tabular}

I mRNA positions are referred to the following human mRNAs: DEFBI07 = [GenBank:AY I22467]; DEFBI05 = [GenBank:NM I52250]; DEFBI06 = [GenBank:NM_I5225I]; DEFBI 04 = [GenBank:NM_080389], DEFB4 = [GenBank:NM_004942]; DEFB $108=[$ GenBank:AF540980]; DEFBI09p = [GenBank:AF54098I].

${ }^{2}$ Haplotypes are derived from the following clones (libraries): $\mathrm{HI}=9$, I0 (both RPII); H2 = 8 (RPI3), I8, I9 (both RPII); H3 = II (RPII); H4 = I2 (RPII); H5 = 13, 14, 29 (all SCb); H6 = 28 (SCb). 


\section{SNPs and haplotypes}

We manually inspected seven clones covering DEF cluster $a$ and 16 clones covering DEF clusters $b 1, b 2$ and $b 3$ for SNPs in exons and introns of all DEF genes. In total we found 270 overlap SNPs: 25 are located in coding sequences, comprising 16 nonsynonymous and nine synonymous changes. 36 SNPs were identified in untranslated regions, and 209 are located in introns. With respect to the coding SNPs in DEF clusters $b$ and regarding 11 of 16 clones, six distinct haplotypes H1-6 can be defined (Table 1). One clone each supports haplotypes H3, H4 and H6, whereas haplotypes $\mathrm{H} 1, \mathrm{H} 2$ and $\mathrm{H} 5$ are found in either two or three clones. The remaining five clones harbor only parts of DEF genes rendering the unambiguous identification of coding SNP based haplotypes impossible. Examination of all SNPs leading to amino acid (aa) changes in defensins indicates that diversity in the peptides is not restricted to residues outside and in between the cystein motif, but also occurs in the vicinity of cysteins, or even a cystein itself is changed (rs1800968 in DEFB1; C67S; data not shown).

\section{Chimpanzee defensin loci}

In order to compare the human chromosome 8p23.1 DEF region to the orthologous locus in our closest relative, we both employed the chimpanzee (Pan troglodytes, ptr) whole genome shotgun (WGS) working draft (WD, [23]) and high quality chimpanzee BAC sequences. Close inspection of the chimpanzee WD scaffold 32935 (chain ID 462) revealed all orthologs of the genes in human $D E F$ cluster a except DEFA3. In contrast to the human organization, ptrDEFA1 and ptrDEFTP were found as single copies. In order to check whether ptrDEFA1 and ptrDEFTP are also multiplied in the ape, but misassembled into a single locus, we inspected the NCBI trace archive [24] for chimpanzee WGS sequences covering the ptrDEFA1 locus. For a region of about 500 bp spanning exon 1 of ptrDEFA1, there are shotgun reads representing six different haplotypes. Since the sequences derived from one chimpanzee this is a clear indication that ptrDEFA1 is also multiplied in the ape. No evidence was found for the presence of ptrDEFA3. Concerning DEF cluster $b$ we encountered the same problem: the cluster is represented only once in the chimpanzee WD (chain ID 900), but trace data inspection indicates the presence of several different haplotypes. Additionally, ptrDEFB108 and ptrDEFB109p are not covered by any chimpanzee WD sequences. As an alternative to the WD approach, we sequenced for ptrDEF cluster $b$ three BAC clones. Examination of SNPs in overlapping regions $(104 \mathrm{~kb})$ of the three clones [GenBank:AC150655], [GenBank:AC150656], [GenBank:AC150657] revealed three different haplotypes originating from one chimpanzee. The detected aa changes in human and chimpanzee defensins are illustrated in Additional file 5. Interestingly, in the ptrDEFA5 protein, one of the disulfide bridging cysteins is changed into serine (C54S). In ptrDEFB108 the canonical cystein motif is truncated (R53opal) which suggests that ptrDEFB108 is a pseudogene, since also the start codon ATG is changed into GTG.

We also used the ptrDEF sequences for the detection of ancestral alleles of all 19 nonsynonymous and synonymous human DEF coding SNPs (Additional file 2).

\section{Individual DEF haplotypes and copy numbers}

In order to determine individual DEF copy numbers we PCR-amplified a 500 bp fragment of DEFB104 which contains 4 SNPs, and a 511 bp region of DEFB4 containing 5 SNPs in four individuals (Table 2). Three of the DEFB4 SNPs (Table 2, SNPs 5,6 and 7) were previously described in a haplotype study in different ethnic populations [25]. The PCR products were cloned, individual clones were sequenced and respective haplotypes were determined according to the base composition at polymorphic positions. Each individual tested bears between three and four different haplotypes of DEFB104 and two to four haplotypes of DEFB4. In different individuals the ratios of the single haplotypes vary remarkably. For instance, at DEFB104 the haplotype GAGC is found in all four individuals but compared to all other haplotypes at ratios of 2:3 (proband 2) to $1: 7$ (proband 1). Interestingly, this haplotype is also found in the trace archives of chimpanzee and baboon. Furthermore, ratios of the individual haplotypes of DEFB104 as well as of DEFB4 indicate different DEF cluster $b$ numbers in the four individuals. While proband 3 bears five copies, proband 4 most probably harbors eight copies or multiples thereof.

\section{Discussion}

The manual clone-by-clone alignment and gene annotation as well as detailed repeat and SNP/haplotype analyses significantly improved the assembly of the human DEF 8p23.1 locus. Eventhough the revised alignment (Fig. $1 \mathrm{~B})$ does not represent a gap-free version of the locus and in fact introduces a second de facto gap, it better reflects the region in the sense of a "human genome reference", since the clones harboring copies of DEF clusters $b$ derive from three libraries (RP11, RP13, SCb) and may therefore represent up to five alleles (library RP13 is represented by only one clone). Our assembly also reflects better the diversity of all available sequence data of this chromosomal region: 27 out of 32 finished clones are incorporated into the tiling path. The remaining five clones cannot be included in the assembly according to our quality criteria and therefore must be regarded as parts of additional copies or alleles. Furthermore we point out that the identification of a third copy of the DEF cluster $b$ in the 360-kb-contig does not represent an allele of clusters $b 1$ or $b 2$ derived from an alternative library / donor, since 
Table 2: Haplotype based estimation of gene and cluster copy numbers

\begin{tabular}{|c|c|c|c|c|c|c|c|c|c|}
\hline \multirow{2}{*}{$\begin{array}{l}\text { Haplotypes } \\
\text { DEFB I } 04\end{array}$} & \multirow[b]{2}{*}{ I } & \multicolumn{3}{|c|}{ SNPI } & & \multicolumn{4}{|c|}{ Proband } \\
\hline & & 2 & 3 & 4 & & $\mathbf{I}$ & 2 & 3 & 4 \\
\hline I & C & $A$ & A & $\mathrm{T}$ & & 50 & 19 & - & 5 \\
\hline 2 & G & $A$ & A & $\mathrm{T}$ & & - & - & 16 & - \\
\hline 3 & G & $A$ & G & C & & 15 & 18 & 32 & 9 \\
\hline 4 & G & G & G & C & & 65 & 10 & 16 & 58 \\
\hline \multirow[t]{3}{*}{5} & G & A & A & $\mathrm{C}$ & & - & - & 14 & - \\
\hline & \multicolumn{5}{|c|}{ Ratios of single haplotypes } & 3:1:4 & 2:2:1 & $1: 2: 1: 1$ & $1: 1: 6$ \\
\hline & \multicolumn{5}{|c|}{ Minimal gene copy number } & 8 & 5 & 5 & 8 \\
\hline DEFB4 & 5 & 6 & 7 & 8 & 9 & $\mathbf{I}$ & 2 & 3 & 4 \\
\hline 1 & C & $\mathrm{C}$ & C & G & A & 14 & - & 8 & - \\
\hline 2 & $\mathrm{C}$ & $\mathrm{T}$ & $\mathrm{G}$ & $\mathrm{G}$ & $A$ & - & 17 & 9 & 5 \\
\hline 3 & $\mathrm{~T}$ & C & C & $A$ & G & 8 & - & 8 & - \\
\hline \multirow[t]{4}{*}{4} & $\mathrm{~T}$ & $\mathrm{C}$ & C & G & G & 24 & 68 & 11 & 30 \\
\hline & \multicolumn{5}{|c|}{ Ratios of single haplotypes } & $2: 1: 3$ & $1: 4$ & I:I:I:I & $1: 6$ \\
\hline & \multicolumn{5}{|c|}{ Minimal Gene copy number } & 6 & 5 & 4 & 7 \\
\hline & \multicolumn{5}{|c|}{ Minimal DEF cluster $b$ copy number } & 8 & 5 & 5 & 8 \\
\hline
\end{tabular}

I SNPI: ss284894|5, 2: rs2680507 = rs| |77403I, 3: ss284894|6, 4: rs4259430, 5: rs2740090, 6: rs274009I, 7: rs27379|2, 8: rs27379|3, 9: rs273753I.

besides four SCb clones one RP11 clone is incorporated. With respect to the RP11 library of which most of the DEF cluster $b$ covering clones derive we conclude that at present sequence information of at least five variants of the cluster is available from a single individual: cluster b1 (clones 9, $10,15) ; b 2$ (clones $16-20$ ); $b 3$ (clone 30); $b 4$ (clone 11) and $b 5$ (clone 12). All these results are in agreement with the reported interindividual variability of DEF cluster $b$ genes [20].

Alignment and analysis of the intergenic distances of clones 4 and 5 (DEF cluster $a$; Fig. 2) show that clone 5 harbors copies 2 and 4 of the four DEFA1 / DEFTP tandems present in clone 4 . Since both clones derive from the same library (SCb), we conclude that either copy 3 of the tandem was lost during the cloning process of clone 5 or the clones represent two different alleles of the same chromosomal locus. This perfectly agrees with the variation in the copy number of DEFA1 reported by Mars [19]. Moreover, the identification of new DEF genes and pseudogenes demonstrates the advantages of a curated manual annotation over automatic approaches.

The LCR analysis (Fig. 3) allows to draw conclusions about the role of these repeats in chromosomal rearrangement processes: The difference in nucleotide identities between LCR II. 1 at one hand and II.2-6 on the other hand indicates that repeats II.2-6 might be involved in rearrangement events of DEF clusters $b$, whereas repeat II.1, separating DEF cluster $a$ from the clusters $b$, has evolved independently from its paralogs. Aditionally, for repeats on chromosome $\mathrm{Y}$, a similar genomic structure as for inverted LCR type II is described in the literature: a 300-kb inverted repeat flanks a $3.5 \mathrm{Mb}$ region that occurs in opposite orientations in different individuals [2]. This supports the assumption that also type II repeats may be involved in homologous recombination events resulting in chromosomal macrorearrangements including inversions, even pericentromeric ones. In particular, this may hold true for the polymorphic 4.7-Mb inv dup del (8p) reported in the literature [16-18]: LCRs of type II are located on chromosome $8 p$ both at 6.9-8.0 Mb and 11.9$12.6 \mathrm{Mb}$ and therefore separated from each other in a range of 3.9-5.7 Mb. Thus, they can be supposed to be inversion breakpoints in REPP and REPD.

The function of the protein encoded by FLJ10408 located in LCR type III is unknown, but the genomic arrangement facilitates proteome plasticity by multiple copies of the same gene.

SNP detection and correct assignment to regions with segmental duplications is not trivial and hampered by paralogous sequence variations [26], duplicon SNPs and multisite variations [6]. Moreover, there is considerable evidence that gene conversion $[27,28]$ promotes allele plasticity in duplicated regions. This is illustrated by the fact that in the UCSC browser 2800 SNPs from dbSNP [29] are assigned to DEF cluster a (224 kb) and the two DEF clusters $b$ (196 kb each) resulting in a SNP density of 1 SNP per $220 \mathrm{bp}$. Close examination indicates that the SNPs are arbitrarily allocated to the two DEF cluster $b$ loci present in the hg16 assembly. Therefore, in such regions, only manual clone-by-clone inspection as performed dur- 
ing our assembly process provides a reliable set of SNPs for the determination of haplotypes. Human SNPs such as rs1800968 in DEFB1, affecting cysteins (C67S) might be of functional relevance, since the cystein connectivity is assumed to determine the correct fold of the defensins which is essential to elicit chemotactic responses as shown for DEFB103 [30].

In order to answer the question whether the extraordinary complexity of the DEF locus is human specific, we closely inspected the orthologous region of the chimpanzee WD. In contrast to the human organization, ptrDEFA1 and ptrDEF cluster $b$ were found as single copies. Familiar with the drawbacks of the WGS automatic assembly [31,32], we suspected these loci are also multiplied in the ape, but assembled wrongly into a single locus due to the high nucleotide identity. In accordance with this assumption, we identified WGS reads representing more than two haplotypes in one chimpanzee. In order to overcome the WD problems we sequenced BAC clones containing ptrDEF cluster $b$ according to a high quality standard and conclude that it is at least duplicated. This suggests that the DEF locus of the chimpanzee is probably as complex as in humans.

The exceptional genomic complexity and heterogeneity of the human 8p23.1 DEF locus and the prominent position of defensins in the innate immunity framework raise the question whether individual patterns of haplotypes together with their variable copy number affect the functionality of the defensin system. A similar situation is found for a chemokine gene cluster where an individually variable gene copy number of CCL3-L1 regulates the gene's expression and is supposed to affect the susceptibility to and progression of inflammatory diseases [33]. Systematic typing of physically linked SNPs should allow to detect interindividual differences in haplotypes and locus copy numbers. Sequencing provides a robust method for the determination of haplotypes and their frequencies scalable to large numbers as required for association studies. As outlined above, SNP genotyping in duplicated regions is demanding and in addition to very careful initial data mining and laboratory practice requires methods allowing the quantitative assessment of allele ratios like dynamic allele-specific hybridization [34] and pyrosequencing [35] as well as of copy-number-variation like multiplex ligation-dependent probe amplification $[36,37]$ and representational oligonucleotide microarray analysis $[38,39]$. In order to differentiate between valid SNPs, duplicon SNPs, paralogous sequence variations and multisite variations, complete hydatidiform moles or haploid genomes have to be included in upstream assay validation [6]. Nevertheless, for highly complex and polymorphic regions the significance of single SNP based assays may be insufficient. As shown in our approach, sys- tematic typing of linked SNPs can overcome this limitation. An estimation of haplotype ratios provides information about the copy number, however, it depends on the number of individual clones analyzed. Our results confirm that the easy-to-handle "classical sequencing approach" is a valuable tool for the determination of DEF gene variants, DEF haplotypes and DEF cluster copy numbers. More detailed analyses will give a catalog of haplotype combinations associated with different phenotypes and diseases. Finally, the presented work provides a set of SNPs and haplotypes suitable for future studies of interindividual DEF locus variability and its disease association.

\section{Conclusions}

Complexity and variability seem to be essential genomic features of the major human DEF locus and of - yet unknown - functional significance for the innate immunity framework. This is supported by our human-chimpanzee genomic comparison. In conclusion of the presented repeat analyses we propose a model of the repeat and DEF cluster organization (Additional file 6) that is consistent with the available sequence information and explains the observed extensive variability of the locus. Since all proposed structural elements of the highly complex locus are available at least once as finished sequence, no fosmid-end mapping problems have been observed (International Human Genome Sequencing Consortium, unpublished results). This is a strong indication that despite there are at least two de facto gaps no essential elements of the DEF locus are missing in the human reference sequence. In comparison to its actual representation, our revised clone alignment clearly better represents the 8p23.1 complexity and improves the human reference sequence as an invaluable resource for the investigation of individual genetic variations. Finally, the presented work provides a set of SNPs and haplotypes as well as a robust sequencing based method suitable for future studies of interindividual DEF locus variability and its disease association.

\section{Methods \\ Alignment revision}

Clone alignments were performed using the GAP4 assembly program, version 6 [40], using the sequences of the GenBank versions listed in the legend of Fig. 1 and Additional file 1. Additionally, for all clones sequenced at the IMB Jena the original GAP4 projects including the trace data were used. The clones were joined allowing only single base exchanges and insertions/deletions in repeat stretches. Joins were not performed if the total ratio of single base differences in the overlapping clone portions exceeded $0.8 \%$. 


\section{Repeat analysis}

LCRs were identified by application of the Miropeats program [41] to the revised alignment. The repeat sequences were extracted from the revised alignment of joined clones following the positions of the Miropeat's output and checked for their nucleotide identity using sim2 [42] and Blast $2.0[43,44]$. Interspersed repeats in the repeat blocks were identified by RepeatMasker (Version: 20040306-web; [45]. Paralogs of the repeat blocks were identified by Blat [46] to the July 2003 UCSC version h16 [10]. The DNA sequences in between the Blat match limits were fetched from the browser and also analyzed for their similarity to the DEF cluster repeats by Blast and sim.

\section{Chimpanzee BAC clones}

The clones were identified by Blast of the revised alignment consensus to the chimpanzee BAC end sequence database [47]. Subcloning was performed into pUC18 followed by sequencing using dye terminator chemistry and ABI 3730/3700 technology. Base calling and assembly were performed by Phred/Phrap and GAP4 was used for editing and finishing in accordance to the Human Genome Project standards [48].

\section{Sequence annotation}

The gene annotation was performed by using the automated sequence annotation system RUMMAGE [49] and ANA_NOTES, SPANDIT and LACE as a local client of the HAVANA pipeline at the Sanger Institute (Hinxton, UK; [21]. Detailed descriptions of the analysis tools are given by [50] and [51].

\section{Haplotypes and copy numbers}

Genomic DNA was extracted from the blood of four male volunteers using the QIAamp DNA Blood Kit (Qiagen). PCR was performed in a total volume of $25 \mu$ l using ReadyToGo PCR beads (Amersham) with 5 pmoles of each primer and $100 \mathrm{ng}$ of DNA. Cycling conditions were $94^{\circ} \mathrm{C}$ for $30 \mathrm{sec}$ followed by 35 cycles with $94^{\circ} \mathrm{C}$ for $20 \mathrm{sec}$, $58^{\circ} \mathrm{C}$ for $30 \mathrm{sec}$ and $72^{\circ} \mathrm{C}$ for $60 \mathrm{sec}$, plus a final $72^{\circ} \mathrm{C}$ extension for $10 \mathrm{~min}$. Oligos used were for $D E F B 4$ GGCGATACTGACACAGGGTT (sense) and ATGGGGAAGGTCAAGGAATC (antisense) and for DEFB104 TTCTGTAGCCCCAACACCTC (sense) and GGTGCCAAGGACATCTAGGA (antisense), respectively. PCR products were cloned into PCRTopo2.1 (Invitrogen) and individual clones were sequenced as described above.

\section{List of abbreviations}

BAC Bacterial artificial chromosome

\section{DEF Defensin}

FISH Fluorescence in situ hybridization
GAP Genome assembly program

HAVANA Human and vertebrate analysis and annotation initiative

LCR Low copy repeat

NCBI National Center for Biotechnology Information

PCR Polymerase chain reaction

ptr Pan troglodytes (chimpanzee)

SNP Single nucleotide polymorphism

UCSC University of California Santa Cruz

WD Working draft

WGS Whole genome shotgun

\section{Author's contributions}

ST performed the assembly revision, the gene annotations, the LCR, SNP and chimpanzee sequence analyses and drafted the manuscript. PG performed mapping and repeat analyses in the 8p23.1 region, completed by IFL's FISH experiments. KR contributed to the sequencing process of clones in the region. AS, SA, NS, KS and MS accounted for the assembly revision and the LCR analyses. $\mathrm{AF}$ and RS supported the gene annotations and the DEF structure and function discussions. $\mathrm{KH}$ and $\mathrm{KR}$ were in charge for the individual haplotype and copy number determinations. MP conceived, designed and coordinated the project.

\section{Additional material}

\section{Additional File 1}

Accession numbers, libraries and clone names of all clones shown in main text, Fig. 1.

Click here for file

[http://www.biomedcentral.com/content/supplementary/1471-

2164-5-92-S1.pdf] 


\section{Additional File 3}

LCR of clones SCb-561b17 [GenBank:AF238378]; green/yellow signals) and CTB-415D8 [GenBank:AF228730]; red signals) visualized by FISH on metaphase chromosomes according to standard protocols [52,53]. Metaphase spread after DAPI counter stain (A) and color inversion (B). Targeted chromosomes are numbered in B. Any FISH signal is shown quadruplicated within the metaphase spread on four chromatides from two homologue chromosomes. Probe CTB-415D8 generated strong FISH signals with declining intensity at $8 p 23,4 p 16,11 q 13.3$ and 3q21, corresponding to the in silico identified LCR type II paralogs (see Fig. 3, main text). Additional weaker signals at 3p12-13, 7q21, 11p15, 12p13 and $16 p 13.3$ are also an indication for LCR type II and III paralogs. In contrast, the single locus of $S C b-561 b 17$ at 8p23 highlighted by open triangles corresponds to the unique LCR type I. Double signals, resulting from two close located targets at $4 p 16,8 p 23$ and $3 q 21$ are marked by asterisks (compare also Additional_file_4).

Click here for file

[http://www.biomedcentral.com/content/supplementary/14712164-5-92-S3.pdf]

\section{Additional File 4}

Resolving LCR type II and III "pairs" on chromosomes at approx. 900 band stage. Probe CTB-415D8 [GenBank:AF228730]; LCR type II and III) generates two clearly separated FISH signals at $4 p 16$ and $8 p 23$, respectively (red signals marked by double arrows): In contrast, probe SCb-561b17 [GenBank:AF238378]; LCR type I) yield a single signal at $8 p 23$, solely (green/yellow signal, open triangle), that is co-localized with the telomeric signal of probe CTB-415D8 [GenBank:AF228730]. Signals with lower intensity are indeterminable in this picture.

Click here for file

[http://www.biomedcentral.com/content/supplementary/14712164-5-92-S4.pdf]

\section{Additional File 5}

DEF aa sequences with highlighted residues (bold) different between human and chimpanzee. Boxes: human aa - human position - chimpanzee aa. All aa positions refer to the following human protein accessions: DEFA6 = [GenBank:NP_001917]; DEFA4 = [GenBank:NP_001916]; DEFA1 $=[$ GenBank:NP_004075] $;$ DEFA5 $=[$ GenBank:NP_066290]; DEFB1 $=[$ GenBank:NP_005209]; DEFB107 $=[$ Gen -

Bank:AAM93909]; DEFB105 = [GenBank:NP_689463]; DEFB103 = [GenBank:NP_061131]; DEFB4 = [GenBank:NP_004933]; DEFB108 $=$ [GenBank:AAN33116]. Aa for the chimpanzee orthologs ptrDEFAG, ptrDEFA4, ptrDEFA1, ptr novel defensin similar to DEFA4, ptrDEFA5 and ptrDEFB1 (ptrDEF cluster a) are deduced from the chimpanzee WD and might therefore include sequencing errors. Those for ptrDEFB1, ptrDEFB107, ptrDEFB105, ptrDEFB103, ptrDEFB4 and ptrDEFB108 (DEF cluster $\mathrm{b}$ ) are derived from high quality $B A C$ sequences and the appropriate traces were visually inspected. The gray shadow indicates the motif of six cystein residues (except for DEFB107 with only five cysteins). Click here for file

[http://www.biomedcentral.com/content/supplementary/14712164-5-92-S5.pdf]

\section{Additional File 2}

Synonymous and non synonymous changes by SNPs in human DEF genes and their ancestral alleles by comparison to chimpanzee sequences.

Click here for file

[http://www.biomedcentral.com/content/supplementary/14712164-5-92-S2.pdf]

\section{Additional File 6}

Predicted genomic organization of the human 8 p23.1 DEF locus. For simplicity only the DEF clusters (arrows) as well as LCRs type II (rectangles) are shown. Black: high quality sequence available; Gray: hypothetical structures, no finished sequence available. In addition to a 'minimal' DEF locus consisting of one $\mathbf{a}$ and two $\mathbf{b}$ clusters (middle), individual loci may have incorporated variable numbers $(\boldsymbol{F}, \boldsymbol{R})$ of additional $\mathrm{b}$ clusters in either orientation. The proposed duplicon consists of two inverted LCRs flanking a DEF cluster b (top/bottom). The orientation of any DEF cluster $\mathrm{b}$ can change either by inverted duplication/crossover (i) or homologous recombination within inverted LCRs ( $x$, right). Moreover, the proposed genomic structure indicates that even in a 'minimal' DEF locus one or both DEF clusters may be deleted due to homologous recombination between direct LCR copies (A). Sequence features of the most distal LCR (II.1; see text and Fig. 3) suggest, that it may be less often involved in recombination or gene conversion events.

Click here for file

[http://www.biomedcentral.com/content/supplementary/14712164-5-92-S6.pdf]

\section{Acknowledgements}

The authors thank Ivonne Heinze, Dorothee Lagemann and Uta Petz for their skillful technical assistance. We would like to thank Jennifer Ashhurst, Tim Hubbard and James Gilbert (Sanger Institute, Hinxton, UK) for their support in installing and maintaining a local client of the HAVANA pipeline. Clones 4, 5, 6, 13, 14, 24, 25, 26, 27, 28, 29 (Fig. I and Additional file I) were provided by Brian Schutte (Dept. of Pediatrics, University of lowa, USA). Chimpanzee BACs [GenBank:ACI50655], [GenBank:ACI 50656], [GenBank:ACI50657] were provided by Asao Fujiyama (RIKEN Genomic Science Center, Japan). We acknowledge the support by the German Human Genome Project grants 0IKW9706 and 0IKW0002.

\section{References}

I. Eichler EE, Clark RA, She $X$ : An assessment of the sequence gaps: unfinished business in a finished human genome. Nat Rev Genet 2004, 5:345-354.

2. Tilford CA, Kuroda-Kawaguchi T, Skaletsky H, Rozen S, Brown LG, Rosenberg M, McPherson JD, Wylie K, Sekhon M, Kucaba TA, Waterston $\mathrm{RH}$, Page DC: A physical map of the human $\mathbf{Y}$ chromosome. Nature 200I, 409:943-945.

3. Locke DP, Segraves R, Nicholls RD, Schwartz S, Pinkel D, Albertson DG, Eichler EE: BAC microarray analysis of $|5 q| \mathrm{I}-\mathrm{q} \mid \mathbf{3}$ rearrangements and the impact of segmental duplications. J Med Genet 2004, 41:175-182.

4. Hillier LW, Fulton RS, Fulton LA, Graves TA, Pepin KH, WagnerMcPherson C, Layman D, Maas J, Jaeger S, Walker R, Wylie K, Sekhon M, Becker MC, O'Laughlin MD, Schaller ME, Fewell GA, Delehaunty KD, Miner TL, Nash WE, Cordes M, Du H, Sun H, Edwards J, Bradshaw-Cordum H, Ali J, Andrews S, Isak A, Vanbrunt A, Nguyen C, Du F, Lamar B, Courtney L, Kalicki J, Ozersky P, Bielicki L, Scott K, Holmes A, Harkins R, Harris A, Strong CM, Hou S, Tomlinson C, Dauphin-Kohlberg S, Kozlowicz-Reilly A, Leonard S, Rohlfing T, Rock SM, Tin-Wollam AM, Abbott A, Minx P, Maupin R, Strowmatt C, Latreille P, Miller N, Johnson D, Murray J, Woessner JP, Wendl MC, Yang SP, Schultz BR, Wallis JW, Spieth J, Bieri TA, Nelson JO, Berkowicz N, Wohldmann PE, Cook LL, Hickenbotham MT, Eldred J, Williams D, Bedell JA, Mardis ER, Clifton SW, Chissoe SL, Marra MA, Raymond C, Haugen E, Gillett W, Zhou Y, James R, Phelps K, ladanoto S, Bubb K, Simms E, Levy R, Clendenning J, Kaul R, Kent WJ, Furey TS, Baertsch RA, Brent MR, Keibler E, Flicek P, Bork P, Suyama M, Bailey JA, Portnoy ME, Torrents D, Chinwalla AT, Gish WR, Eddy SR, McPherson JD, Olson MV, Eichler EE, Green ED, Waterston RH, Wilson RK: The DNA sequence of human chromosome 7. Nature 2003, 424: $157-164$. 
5. Sebire NJ, Fisher RA, Rees HC: Histopathological diagnosis of partial and complete hydatidiform mole in the first trimester of pregnancy. Pediatr Dev Pathol 2003, 6:69-77.

6. Fredman D, White SJ, Potter S, Eichler EE, Dunnen JT, Brookes AJ: Complex SNP-related sequence variation in segmental genome duplications. Nat Genet 2004, 36:86I-866.

7. Benham F, Hart K, Crolla J, Bobrow M, Francavilla M, Goodfellow PN: A method for generating hybrids containing nonselected fragments of human chromosomes. Genomics 1989, 4:509-5 I7.

8. Bailey JA, Baertsch R, Kent WJ, Haussler D, Eichler EE: Hotspots of mammalian chromosomal evolution. Genome Biol 2004, 5:R23.

9. Schmutz J, Wheeler J, Grimwood J, Dickson M, Yang J, Caoile C, Bajorek E, Black S, Chan YM, Denys M, Escobar J, Flowers D, Fotopulos D, Garcia C, Gomez M, Gonzales E, Haydu L, Lopez F, Ramirez L, Retterer J, Rodriguez A, Rogers S, Salazar A, Tsai M, Myers RM: Quality assessment of the human genome sequence. Nature 2004, 429:365-368.

10. University of California Santa Cruz (UCSC) Genome Browser [http://genome.ucsc.edu/cgi-bin/hgGateway]

II. Ganz T: Defensins: antimicrobial peptides of innate immunity. Nat Rev Immunol 2003, 3:7I 0-720.

12. Schullerus D, von Knobloch R, Chudek J, Herbers J, Kovacs G: Microsatellite analysis reveals deletion of a large region at chromosome 8p in conventional renal cell carcinoma. Int J Cancer 1999, 80:22-24.

13. Young AN, de Oliveira Salles PG, Lim SD, Cohen C, Petros JA, Marshall FF, Neish AS, Amin MB: Beta defensin-I, parvalbumin, and vimentin: a panel of diagnostic immunohistochemical markers for renal tumors derived from gene expression profiling studies using cDNA microarrays. Am J Surg Pathol 2003, 27:199-205

14. Donald CD, Sun CQ, Lim SD, Macoska J, Cohen C, Amin MB, Young AN, Ganz TA, Marshall FF, Petros JA: Cancer-specific loss of betadefensin I in renal and prostatic carcinomas. Lab Invest 2003, 83:50I-505

15. Veltman JA, Fridlyand J, Pejavar S, Olshen AB, Korkola JE, DeVries S, Carroll P, Kuo WL, Pinkel D, Albertson D, Cordon-Cardo C, Jain AN, Waldman FM: Array-based comparative genomic hybridization for genome-wide screening of DNA copy number in bladder tumors. Cancer Res 2003, 63:2872-2880.

16. Giglio S, Broman KW, Matsumoto N, Calvari V, Gimelli G, Neumann $T$, Ohashi H, Voullaire L, Larizza D, Giorda R, Weber JL, Ledbetter $\mathrm{DH}$, Zuffardi $\mathrm{O}$ : Olfactory receptor-gene clusters, genomicinversion polymorphisms, and common chromosome rearrangements. Am J Hum Genet 200I, 68:874-883.

17. Shimokawa O, Kurosawa K, Ida T, Harada N, Kondoh T, Miyake N, Yoshiura K, Kishino T, Ohta T, Niikawa N, Matsumoto N: Molecular characterization of inv dup del(8p): analysis of five cases. $A m$ J Med Genet 2004, I 28A: I33-I37.

18. Sugawara $\mathrm{H}$, Harada N, Ida T, Ishida $\mathrm{T}$, Ledbetter $\mathrm{DH}$, Yoshiura $\mathrm{K}$, Ohta T, Kishino T, Niikawa N, Matsumoto N: Complex low-copy repeats associated with a common polymorphic inversion at human chromosome 8p23. Genomics 2003, 82:238-244.

19. Mars WM, Patmasiriwat P, Maity T, Huff V, Weil MM, Saunders GF: Inheritance of unequal numbers of the genes encoding the human neutrophil defensins HP-I and HP-3. J Biol Chem I995, 270:3037I-30376.

20. Hollox EJ, Armour JA, Barber JC: Extensive normal copy number variation of a beta-defensin antimicrobial-gene cluster. $\mathrm{Am} J$ Hum Genet 2003, 73:591-600.

21. Human and vertebrate analysis and annotation initiative [http://www.sanger.ac.uk/HGP/havana/]

22. Vertebrate Genome Annotation Database [http://
] vega.sanger.ac.uk/]

23. University of California Santa Cruz (UCSC) Home page [http://genome.ucsc.edu/]

24. Trace archive at NCBI [http://www.ncbi.nlm.nih.gov/Traces]

25. Jurevic RJ, Chrisman P, Mancl L, Livingston R, Dale BA: Single-nucleotide polymorphisms and haplotype analysis in beta-defensin genes in different ethnic populations. Genet Test 2002, 6:261-269.

26. Cheung J, Estivill X, Khaja R, MacDonald JR, Lau K, Tsui LC, Scherer SW: Genome-wide detection of segmental duplications and potential assembly errors in the human genome sequence. Genome Biol 2003, 4:R25.
27. Jeffreys AJ, May CA: Intense and highly localized gene conversion activity in human meiotic crossover hot spots. Nat Genet 2004, 36: 151 - 156.

28. Rozen S, Skaletsky H, Marszalek JD, Minx PJ, Cordum HS, Waterston $\mathrm{RH}$, Wilson RK, Page DC: Abundant gene conversion between arms of palindromes in human and ape $\mathbf{Y}$ chromosomes. Nature 2003, 423:873-876.

29. SNP database at NCBI [http://www.ncbi.nlm.nih.gov/SNP/]

30. Wu Z, Hoover DM, Yang D, Boulegue C, Santamaria F, Oppenheim JJ, Lubkowski J, Lu W: Engineering disulfide bridges to dissect antimicrobial and chemotactic activities of human betadefensin 3. Proc Natl Acad Sci U S A 2003, 100:8880-8885.

31. Venter JC, Adams MD, Myers EW, Li PW, Mural RJ, Sutton GG, Smith HO, Yandell M, Evans CA, Holt RA, Gocayne JD, Amanatides P, Ballew RM, Huson DH, Wortman JR, Zhang Q, Kodira CD, Zheng XH, Chen L, Skupski M, Subramanian G, Thomas PD, Zhang J, Gabor Miklos GL, Nelson C, Broder S, Clark AG, Nadeau J, McKusick VA, Zinder N, Levine AJ, Roberts RJ, Simon M, Slayman C, Hunkapiller M, Bolanos R, Delcher A, Dew I, Fasulo D, Flanigan M, Florea L, Halpern A, Hannenhalli S, Kravitz S, Levy S, Mobarry C, Reinert K, Remington K, Abu-Threideh J, Beasley E, Biddick K, Bonazzi V, Brandon R, Cargill M, Chandramouliswaran I, Charlab R, Chaturvedi K, Deng Z, Di Francesco V, Dunn P, Eilbeck K, Evangelista C, Gabrielian AE, Gan W, Ge W, Gong F, Gu Z, Guan P, Heiman TJ, Higgins ME, Ji RR, Ke Z, Ketchum KA, Lai Z, Lei Y, Li Z, Li J, Liang Y, Lin X, Lu F, Merkulov GV, Milshina N, Moore HM, Naik AK, Narayan VA, Neelam B, Nusskern D, Rusch DB, Salzberg S, Shao W, Shue B, Sun J, Wang Z, Wang A, Wang X, Wang J, Wei M, Wides R, Xiao C, Yan C, Yao A, Ye J, Zhan M, Zhang W, Zhang H, Zhao Q, Zheng L, Zhong F, Zhong W, Zhu S, Zhao S, Gilbert D, Baumhueter S, Spier G, Carter C, Cravchik A, Woodage T, Ali F, An H, Awe A, Baldwin D, Baden H, Barnstead M, Barrow I, Beeson K, Busam D, Carver A, Center A, Cheng ML, Curry L, Danaher S, Davenport L, Desilets R, Dietz S, Dodson K, Doup L, Ferriera S, Garg N, Gluecksmann A, Hart B, Haynes J, Haynes C, Heiner C, Hladun S, Hostin D, Houck J, Howland T, Ibegwam C, Johnson J, Kalush F, Kline L, Koduru S, Love A, Mann F, May D, McCawley S, Mclntosh T, McMullen I, Moy M, Moy L, Murphy B, Nelson K, Pfannkoch C, Pratts E, Puri V, Qureshi H, Reardon M, Rodriguez $R$, Rogers $Y H$, Romblad D, Ruhfel B, Scott R, Sitter C, Smallwood M, Stewart E, Strong R, Suh E, Thomas R, Tint NN, Tse S, Vech C, Wang G, Wetter J, Williams S, Williams M, Windsor S, WinnDeen E, Wolfe K, Zaveri J, Zaveri K, Abril JF, Guigo R, Campbell MJ, Sjolander KV, Karlak B, Kejariwal A, Mi H, Lazareva B, Hatton T, Narechania A, Diemer K, Muruganujan A, Guo N, Sato S, Bafna V, Istrail S, Lippert R, Schwartz R, Walenz B, Yooseph S, Allen D, Basu A, Baxendale J, Blick L, Caminha M, Carnes-Stine J, Caulk P, Chiang YH, Coyne M, Dahlke C, Mays A, Dombroski M, Donnelly M, Ely D, Esparham S, Fosler C, Gire H, Glanowski S, Glasser K, Glodek A, Gorokhov M, Graham K, Gropman B, Harris M, Heil J, Henderson S, Hoover J, Jennings D, Jordan C, Jordan J, Kasha J, Kagan L, Kraft C, Levitsky A, Lewis M, Liu X, Lopez J, Ma D, Majoros W, McDaniel J, Murphy S, Newman M, Nguyen T, Nguyen N, Nodell M, Pan S, Peck J. Peterson M, Rowe W, Sanders R, Scott J, Simpson M, Smith T, Sprague A, Stockwell T, Turner R, Venter E, Wang M, Wen M, Wu $D$, Wu M, Xia A, Zandieh A, Zhu X: The sequence of the human genome. Science 200I, 29 I: I304-I35 I.

32. Waterston RH, Lindblad-Toh K, Birney E, Rogers J, Abril JF, Agarwal $\mathrm{P}$, Agarwala R, Ainscough R, Alexandersson M, An P, Antonarakis SE, Attwood J, Baertsch R, Bailey J, Barlow K, Beck S, Berry E, Birren B, Bloom T, Bork P, Botcherby M, Bray N, Brent MR, Brown DG, Brown SD, Bult C, Burton J, Butler J, Campbell RD, Carninci P, Cawley S, Chiaromonte F, Chinwalla AT, Church DM, Clamp M, Clee C, Collins FS, Cook LL, Copley RR, Coulson A, Couronne O, Cuff J, Curwen V, Cutts T, Daly M, David R, Davies J, Delehaunty KD, Deri J, Dermitzakis ET, Dewey C, Dickens NJ, Diekhans M, Dodge S, Dubchak I, Dunn DM, Eddy SR, Elnitski L, Emes RD, Eswara P, Eyras E, Felsenfeld A, Fewell GA, Flicek P, Foley K, Frankel WN, Fulton LA, Fulton RS, Furey TS, Gage D, Gibbs RA, Glusman G, Gnerre S, Goldman N, Goodstadt L, Grafham D, Graves TA, Green ED, Gregory S, Guigo R, Guyer M, Hardison RC, Haussler D, Hayashizaki Y, Hillier LW, Hinrichs A Hlavina W, Holzer T, Hsu F, Hua A, Hubbard T, Hunt A, Jackson I, Jaffe DB, Johnson LS, Jones M, Jones TA, Joy A, Kamal M, Karlsson EK, Karolchik D, Kasprzyk A, Kawai J, Keibler E, Kells C, Kent W], Kirby A, Kolbe DL, Korf I, Kucherlapati RS, Kulbokas EJ, Kulp D, Landers T, Leger JP, Leonard S, Letunic I, Levine R, Li J, Li M, Lloyd C, Lucas S, Ma B, Maglott DR, Mardis ER, Matthews L, Mauceli E, Mayer JH, 
McCarthy M, McCombie WR, McLaren S, McLay K, McPherson JD, Meldrim J, Meredith B, Mesirov JP, Miller W, Miner TL, Mongin E, Montgomery KT, Morgan M, Mott R, Mullikin JC, Muzny DM, Nash WE, Nelson JO, Nhan MN, Nicol R, Ning Z, Nusbaum C, O'Connor MJ, Okazaki Y, Oliver K, Overton-Larty E, Pachter L, Parra G, Pepin $\mathrm{KH}$, Peterson J, Pevzner P, Plumb R, Pohl CS, Poliakov A, Ponce TC, Ponting CP, Potter S, Quail M, Reymond A, Roe BA, Roskin KM, Rubin EM, Rust AG, Santos R, Sapojnikov V, Schultz B, Schultz J, Schwartz MS, Schwartz S, Scott C, Seaman S, Searle S, Sharpe T, Sheridan A, Shownkeen R, Sims S, Singer JB, Slater G, Smit A, Smith DR, Spencer B, Stabenau A, Stange-Thomann N, Sugnet C, Suyama M, Tesler G, Thompson J, Torrents D, Trevaskis E, Tromp J, Ucla C, Ureta-Vidal A, Vinson JP, Von Niederhausern AC, Wade CM, Wall M, Weber RJ, Weiss RB, Wendl MC, West AP, Wetterstrand K, Wheeler R, Whelan S, Wierzbowski J, Willey D, Williams S, Wilson RK, Winter E, Worley KC, Wyman D, Yang S, Yang SP, Zdobnov EM, Zody MC, Lander ES: Initial sequencing and comparative analysis of the mouse genome. Nature 2002, 420:520-562.

33. Townson JR, Barcellos LF, Nibbs RJ: Gene copy number regulates the production of the human chemokine CCL3-LI. Eur J Immunol 2002, 32:3016-3026.

34. Prince JA, Feuk L, Howell WM, Jobs M, Emahazion T, Blennow K, Brookes A): Robust and accurate single nucleotide polymorphism genotyping by dynamic allele-specific hybridization (DASH): design criteria and assay validation. Genome Res 200I, I I:152-162.

35. Utting M, Hampe J, Platzer M, Huse K: Locking of 3' ends of singlestranded DNA templates for improving Pyrosequencing(TM). BioTechniques 2004, 37:66-73.

36. White SJ, Vink GR, Kriek M, Wuyts W, Schouten J, Bakker B, Breuning $\mathrm{MH}$, den Dunnen JT: Two-color multiplex ligation-dependent probe amplification: detecting genomic rearrangements in hereditary multiple exostoses. Hum Mutat 2004, 24:86-92.

37. Schouten JP, McElgunn CJ, Waaijer R, Zwijnenburg D, Diepvens F, Pals G: Relative quantification of $\mathbf{4 0}$ nucleic acid sequences by multiplex ligation-dependent probe amplification. Nucleic Acids Res 2002, 30:e57.

38. Lucito R, Healy J, Alexander J, Reiner A, Esposito D, Chi M, Rodgers L, Brady A, Sebat J, Troge J, West JA, Rostan S, Nguyen KC, Powers S, Ye KQ, Olshen A, Venkatraman E, Norton L, Wigler M: Representational oligonucleotide microarray analysis: a high-resolution method to detect genome copy number variation. Genome Res 2003, 13:2291-2305.

39. Sebat J, Lakshmi B, Troge J, Alexander J, Young J, Lundin P, Maner S, Massa $H$, Walker M, Chi M, Navin N, Lucito R, Healy J, Hicks J, Ye K, Reiner A, Gilliam TC, Trask B, Patterson N, Zetterberg A, Wigler M: Large-scale copy number polymorphism in the human genome. Science 2004, 305:525-528.

40. Bonfield JK, Smith K, Staden R: A new DNA sequence assembly program. Nucleic Acids Res 1995, 23:4992-4999.

4I. Miropeats program [http://genome.wustl.edu/groups/informatics/ software/miropeats/]

42. Chao KM, Zhang J, Ostell J, Miller W: A local alignment tool for very long DNA sequences. Comput Appl Biosci 1995, I I:I47-I53.

43. WU-Blast [http://blast.wustl.edu]

44. Altschul SF, Madden TL, Schaffer AA, Zhang J, Zhang Z, Miller W, Lipman DJ: Gapped BLAST and PSI-BLAST: a new generation of protein database search programs. Nucleic Acids Res 1997, 25:3389-3402.

45. Repeatmasker program [http://www.repeatmasker.org/cgi-bin/ WEBRepeatMasker]

46. Kent WJ: BLAT-the BLAST-like alignment tool. Genome Res 2002, I 2:656-664.

47. RIKEN chimpanzee BAC end sequence database [http:// hgp.gsc.riken.go.jp]

48. Finishing Standards for the Human Genome Project [http:// genome.wustl.edu/Overview/gl6stand.php]

49. Taudien S, Rump A, Platzer M, Drescher B, Schattevoy R, Gloeckner G, Dette M, Baumgart C, Weber J, Menzel U, Rosenthal A: RUMMAGE-a high-throughput sequence annotation system. Trends Genet 2000, 16:519-520.

50. Hubbard T, Barker D, Birney E, Cameron G, Chen Y, Clark L, Cox T, Cuff J, Curwen V, Down T, Durbin R, Eyras E, Gilbert J, Hammond M, Huminiecki L, Kasprzyk A, Lehvaslaiho H, Lijnzaad P, Melsopp C, Mongin E, Pettett R, Pocock M, Potter S, Rust A, Schmidt E, Searle S, Slater G, Smith J, Spooner W, Stabenau A, Stalker J, Stupka E, Ureta-
Vidal A, Vastrik I, Clamp M: The Ensembl genome database project. Nucleic Acids Res 2002, 30:38-4I.

5I. Benson G: Tandem repeats finder: a program to analyze DNA sequences. Nucleic Acids Res 1999, 27:573-580.

52. Verma RS, Babu A: Human Chromosomes 2nd edition. Pergamon Press Inc; 1989.

53. Nietzel A, Rocchi M, Starke H, Heller A, Fiedler W, Wlodarska I, Loncarevic IF, Beensen V, Claussen U, Liehr T: A new multicolorFISH approach for the characterization of marker chromosomes: centromere-specific multicolor-FISH (cenM-FISH). Hum Genet 200I, 108:199-204.
Publish with Bio Med Central and every scientist can read your work free of charge

"BioMed Central will be the most significant development for disseminating the results of biomedical research in our lifetime. "

Sir Paul Nurse, Cancer Research UK

Your research papers will be:

- available free of charge to the entire biomedical community

- peer reviewed and published immediately upon acceptance

- cited in PubMed and archived on PubMed Central

- yours - you keep the copyright

Submit your manuscript here:

http://www.biomedcentral.com/info/publishing_adv.asp
BiolMedcentral 